\title{
Impact of Premature Greying of Hair on Socio- cultural Adjustment and Self-esteem among Medical Undergraduates in Foundation University, Islamabad
}

\author{
Muhammad Saad ${ }^{1}$, Nabeela Fazal Babar ${ }^{2}$, Ramsha Majeed ${ }^{1}$, Ateeq Ur Rehman ${ }^{1}$, Omair A. Khan ${ }^{1}$, Danyal \\ E. Chatha ${ }^{1}$, Urooj Aamir ${ }^{1}$, Amna Nadeem ${ }^{3}$, Sayeddah Abbas ${ }^{4}$ \\ 1. Internal Medicine, Fauji Foundation Hospital, Rawalpindi, PAK 2. Community Medicine, Foundation University \\ Medical College, Rawalpindi, PAK 3. Rehabilitation, Fauji Foundation Hospital, Rawalpindi, PAK 4. Biochemistry, Fauji \\ Foundation Hospital, Rawalpindi, PAK
}

Corresponding author: Omair A. Khan, omair.khn@outlook.com

\section{Abstract}

\section{Introduction}

Greying of hair is an inevitable phenomenon that occurs commonly as a person ages. It usually occurs in the fourth decade regardless of gender but now a days, even people in their early twenties can experience premature greying. The objective of our study was to determine the frequency of premature greying of hair and its impact on the socio-cultural spheres of life and self-esteem of medical students.

\section{Methodology}

It is a descriptive cross-sectional study conducted at Foundation University Medical College (FUMC) from January to February 2017. All medical students of FUMC who gave their consent were included in the study sample. Students who were absent or unwilling to participate were excluded. Data was collected through a self-administered questionnaire, which was then analysed using SPSS version 17 (SPSS Inc., Chicago, IL).

\section{Results}

Out of 673 students, 210 (31.2\%) suffered from premature greying of hair. The prevalence was higher among females $(155 / 73.8 \%)$ as compared to males $(55 / 26.2 \%)$. There was a statistical difference in perception of both the genders, regarding those with premature greying of hair trying to hide it ( $\mathrm{p}$-value $=0.000$ ), premature greying of hair as contagious ( $(\mathrm{p}$-value $=.009)$ and the affected looking older than their actual age $(\mathrm{p}$-value $=0.036)$.

\section{Conclusion}

Received 06/06/2019 Review began 06/19/2019 Review ended 06/28/2019 Published 07/04/2019

\section{() Copyright 2019}

Saad et al. This is an open access article distributed under the terms of the Creative Commons Attribution License CC-BY 3.0., which permits unrestricted use, distribution, and reproduction in any medium, provided the original author and source are credited.
The study showed that premature greying affected the socio-cultural spheres of students' lives. Females were more prone to developing premature greying of hair. Genetics also play a significant role in the phenomenon. No positive correlation was found by using Rosenberg Self-esteem scale.

\author{
Categories: Genetics, Psychology, Quality Improvement \\ Keywords: self-esteem, premature greying of hair, socio-cultural
}

\section{Introduction}

Hair greying or canities is a normal phenomenon occurring as one ages, but some individuals experience hair greying at a much earlier age. Hair contains melanin, a pigment whose production is determined by the genetic makeup of a person. Melanin gives colour to our hair, eyes and skin. The process of hair greying has been attributed to the loss of pigment forming melanocytes, which are the product of a complex biological pathway, i.e., melanogenesis [1]. Although hair greying or canities is a natural process occurring in people as they age, an unknown percentage of individuals experience premature greying from familial inheritance or pathologic conditions. It has been ascertained that grey hair does not contain any melanocytes, or it contains very few which are inactive [2]. The occurrence of pigmentation is an important phenotype of humans. The exact etiology for premature greying of hair (PGH) remains uncertain to this day but low serum calcium, serum ferritin and vitamin D3 levels have been linked to premature greying of hair [3]. A decrease in the synthesis of melanin is associated with the reduced activity of tyrosine. Free radical theory of hair greying has also been suggested [4]. PGH has been found to be associated with a number of autoimmune diseases, disorders of endocrine systems, UV radiation, drugs, smoking, deficiencies of trace elements and nutritional deficiencies. Calcium and vitamin D3 deficiencies play a less prominent role. It is an indicator for either genetic diseases or non-genetic diseases such as myocardial infarction, congestive heart failure, stroke, liver cirrhosis, or cancer [5,6]. 


\section{Cureus}

Premature greying of hair is seen among young adults; starting in Caucasians before the age of 20 years, while in Africans before the age of 30 years. Due to an increase in its incidence more people are giving medical attention to its psychological effects [7]. Studies regarding loss of hair pigmentation and associated factors have been done in other Asian countries like Turkey and India $[8,9]$. The lack of studies conducted in our area of the world, however, prompted us to perform a cross-sectional study among medical students to determine the frequency of premature greying of hair (PGH), how PGH affects psychological health, sociocultural adjustment and issues rooting from low self-esteem in medical students.

\section{Materials And Methods}

It is a descriptive cross-sectional study conducted in Foundation University Medical College (FUMC) Islamabad from January to February 2017. Target population were medical students of Foundation University Islamabad Campus. All medical students of FUMC who gave their consent were included in study sample. Students who were absent or unwilling to participate were excluded. A sample size of 446 was calculated at a $95 \%$ confidence interval and $5 \%$ sample error with a prevalence of $50 \%$. Effect on sociocultural adjustment was assessed by using a preformed \& pretested questionnaire which was distributed in classrooms and re-collected after 15-20 minutes. Approval for the project was obtained from the local ethical committee. The questionnaire used in this study had several parts, including;

- Socio-demographic part.

- Perception of students about premature greying.

- Cause ordered on five-level Likert Scale (Strongly agree, Agree, Neutral, Disagree, Strongly disagree).

- Social and cultural impact of premature greying of hair in both the genders.

The impact on self-esteem was calculated by using Rosenberg Self-esteem Scale. Simple tables were made for each variable, showing the results in numbers and percentages. Data analysis was done by using SPSS version 17 (SPSS Inc., Chicago, IL). Descriptive statistics including means, standard deviations, and frequencies were assessed on variables. Chi-square test was used for quantitative variables.

\section{Results}

The study sample consisted of 673 medical students from first year to final year. Mean age of the students was $20.94 \mathrm{yr} \pm 1.85$ standard deviation. Most of the students, i.e. 490 (72.8\%) students, were between the ages of 19-22 year whereas between 17-18 year were 46 (6.8\%) and 23-26 were 137 (20.3\%) students. Refer to Table 1 .

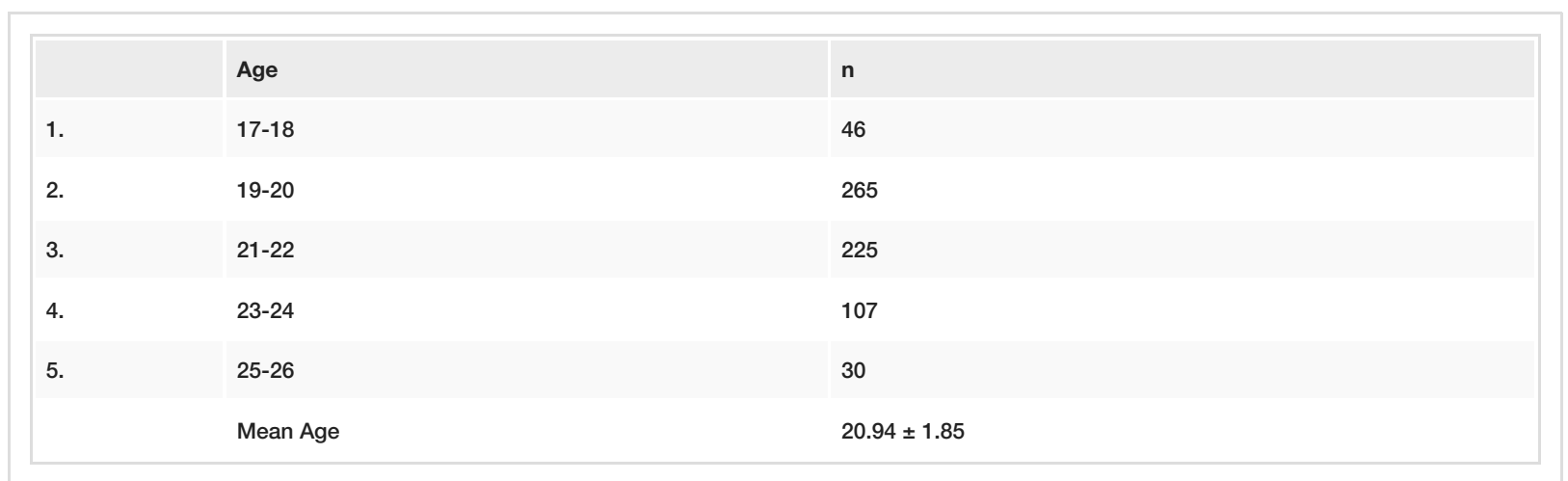

TABLE 1: Age of study participants

Out of 673 students, 500 (74.3\%) were females and 173 (25.7\%) were males. It showed female predominance.

A total of 210 (31.2\%) study participants have experienced premature greying of hair. Significant number of participants had reported early greying of hair. See Table 2 . 


\section{Cureus}

Are you affected by premature greying of hair?

n (\%)

Yes

$210(31.2 \%)$

No

$463(68.8 \%)$

TABLE 2: Prevalence of premature greying of hair

Overall prevalence was 210 (31.2\%) out of 673 students participated. Third year had maximum reporting of premature greying of hair whereas 5 th year had least number of students affected. Females were affected more. See Table 3.

\begin{tabular}{|c|c|c|c|}
\hline Year & Male & Female & Total n (\%) \\
\hline Prevalence in $1^{\text {st }}$ year & 10 & 29 & 39 (18.57\%) \\
\hline Prevalence in $2^{\text {nd }}$ year & 11 & 33 & 44 (20.95\%) \\
\hline Prevalence in $3^{\text {rd }}$ year & 13 & 34 & 47 (22.38\%) \\
\hline Prevalence in $4^{\text {th }}$ year & 13 & 32 & $45(21.42 \%)$ \\
\hline \multirow[t]{2}{*}{ Prevalence in $5^{\text {th }}$ year } & 8 & 27 & 35 (16.66\%) \\
\hline & & & Total $=210(100 \%)$ \\
\hline
\end{tabular}

TABLE 3: Class- and gender-wise distribution

When asked, students strongly agreed that genetics, malnutrition and erratic lifestyle played an important role in the onset of premature greying of hair. Junk food, smoking, obesity and blood donation were not a risk factor for premature greying of hair. See Table 4.

\begin{tabular}{|c|c|c|c|c|c|c|}
\hline \multicolumn{2}{|c|}{ Factors responsible for premature greying of hair } & \multirow{2}{*}{$\begin{array}{l}\text { Strongly disagree } \\
70(10.4 \%)\end{array}$} & \multirow{2}{*}{$\begin{array}{l}\text { Disagree } \\
39(5.79 \%)\end{array}$} & \multirow{2}{*}{$\begin{array}{l}\text { Neutral } \\
45(6.68 \%)\end{array}$} & \multirow{2}{*}{$\begin{array}{l}\text { Agree } \\
206(30.60)\end{array}$} & \multirow{2}{*}{$\begin{array}{l}\text { Strongly agree } \\
313(46.50 \%)\end{array}$} \\
\hline 1 & Genetics & & & & & \\
\hline 2 & Junk food & $142(21.09 \%)$ & $176(26.15 \%)$ & $195(28.97 \%)$ & $105(15.60 \%)$ & $55(8.17 \%)$ \\
\hline 3 & Smoking & $78(11.58 \%)$ & $149(22.13 \%)$ & $201(29.86 \%)$ & $167(24.81 \%)$ & $78(11.58 \%)$ \\
\hline 4 & Obesity & $125(18.57 \%)$ & $198(29.42 \%)$ & $212(31.50 \%)$ & $89(13.22 \%)$ & $49(7.28 \%)$ \\
\hline 5 & Malnutrition & 75 (11.14\%) & $83(12.33 \%)$ & $125(18.57 \%)$ & $232(34.47 \%)$ & $158(23.47 \%)$ \\
\hline 6 & Erratic lifestyle & $72(10.69 \%)$ & $111(16.49 \%)$ & $196(29.12 \%)$ & $200(29.71 \%)$ & $94(9.50 \%)$ \\
\hline 7 & Blood donation & 239 (35.51\%) & $151(22.43 \%)$ & 164 (24.36\%) & 68 (10.10\%) & $51(7.57 \%)$ \\
\hline
\end{tabular}

TABLE 4: Factors responsible for causing premature greying of hair

When the students were asked when they considered greying of hair as premature, most of the students, i.e. 257 (38.18\%), believed it started around the age of 16-20. Students believed that premature greying of hair was not associated with a lack of self-care. However, a sizeable portion believed that it might be associated with the use of excessive cosmetic hair products and inadequate oiling. Refer to Table 5 for more details. 


\section{Cureus}

\begin{tabular}{|c|c|c|c|c|c|}
\hline \multirow{3}{*}{$\begin{array}{l}\text { When do you consider greying of } \\
\text { hair as premature? }\end{array}$} & \multicolumn{5}{|l|}{ Options, n\% } \\
\hline & $10-15$ years & $\begin{array}{l}16-20 \\
\text { years }\end{array}$ & $21-25$ years & $26-30$ years & More than 30 \\
\hline & $151(22.44 \%)$ & $\begin{array}{l}257 \\
(38.19 \%)\end{array}$ & $133(19 . \% \%)$ & $90(13.3 \%)$ & $42(6.24 \%)$ \\
\hline \multirow{2}{*}{ Is it associated with self-care? } & $\begin{array}{l}\text { Inadequate oiling } \\
\text { of scalp }\end{array}$ & \multicolumn{2}{|c|}{$\begin{array}{l}\text { Use of cosmetic/hair } \\
\text { products }\end{array}$} & Inadequate washing & $\begin{array}{l}\text { Not associated with lack of } \\
\text { self-care }\end{array}$ \\
\hline & 95 (14.1\%) & \multicolumn{2}{|c|}{$178(26.4 \%)$} & $25(3.7 \%)$ & 375 (55.7\%) \\
\hline
\end{tabular}

TABLE 5: Perception about age of greying as premature and self-care related

When asked, the affected students reported noticing greying of hair for the first time around the age of 1620 years. The students mostly used different styling techniques to hide their grey hair as well as dying techniques. Anxiety, mood fluctuation, concentration at work, interpersonal relationship and treatmentrelated questions did not reveal any positive responses. Fifty-seven (27.1\%) students believed that they looked older than their actual age while many denied this. Refer to Table 6 for more details. 


\section{Cureus}

\begin{tabular}{|c|c|c|c|}
\hline Sr. No & Variable & Frequency & Percentage \\
\hline \multirow{5}{*}{1} & First noticed PGH at the Age of? & & \\
\hline & Less than 16 years & 47 & $22.38 \%$ \\
\hline & $16-20$ years & 116 & $55.23 \%$ \\
\hline & $21-25$ years & 30 & $14.28 \%$ \\
\hline & Other & 17 & $8.09 \%$ \\
\hline \multirow{5}{*}{2} & How do you hide your grey hair? & & \\
\hline & Dyeing & 59 & $28.09 \%$ \\
\hline & Styling & 93 & $44.28 \%$ \\
\hline & Wear cap & 11 & $5.23 \%$ \\
\hline & Covering & 47 & $22.38 \%$ \\
\hline \multirow{3}{*}{3} & Felt guilty/anxiety about having grey hair? & & \\
\hline & No & 147 & $70 \%$ \\
\hline & Yes & 63 & $30 \%$ \\
\hline \multirow{3}{*}{4} & Fluctuations in mood due to grey hair? & & \\
\hline & No & 177 & $84.28 \%$ \\
\hline & Yes & 33 & $15.71 \%$ \\
\hline \multirow{3}{*}{5} & Does PGH affect your concentration at work? & & \\
\hline & No & 174 & $85.85 \%$ \\
\hline & Yes & 36 & $17.14 \%$ \\
\hline \multirow{3}{*}{6} & Does PGH affect your interpersonal relationship? & & \\
\hline & No & 173 & $82.38 \%$ \\
\hline & Yes & 37 & $17.61 \%$ \\
\hline \multirow{3}{*}{7} & Feel the need for treatment? & & \\
\hline & No & 139 & $66.19 \%$ \\
\hline & Yes & 71 & $33.81 \%$ \\
\hline
\end{tabular}

\section{TABLE 6: Psychological impact on students affected by premature greying of hair in study}

population $(n=210)$

PGH: Premature greying of hair

As depicted in the following Table 7, there was a statistical difference in perception of both the genders regarding, those with premature greying of hair try to hide it ( $p$-value $=0.000$ ), premature greying of hair is contagious ( $p$-value $=.009$ ) whereas no statistically difference was found regarding their opinion on how frequently greying of hair is noticed ( $\mathrm{p}$-value $=.011$ ), if premature greying of hair is a sign of old age and loss of health ( $p$-value $=0.215$ ) and premature greying of hair hinders one from participating in social activities $(\mathrm{p}$-value $=0.115)$. 


\section{Cureus}

\begin{tabular}{|c|c|c|c|c|}
\hline Sr. No. & Variable & Gender & & P-value \\
\hline \multirow{4}{*}{1} & & Male & Female & \multirow{4}{*}{0.113} \\
\hline & & No. $\%$ & No. $\%$ & \\
\hline & No & $58(8.61 \%)$ & $136(20.20 \%)$ & \\
\hline & Yes & $115(17.08 \%)$ & $364(54.08 \%)$ & \\
\hline \multirow{3}{*}{2} & People with PGH try to hide it? & & & \multirow{3}{*}{0.000} \\
\hline & No & $62(9.21 \%)$ & $107(15.89 \%)$ & \\
\hline & Yes & $111(16.49 \%)$ & $393(58.39 \%)$ & \\
\hline \multirow{3}{*}{3} & $\mathrm{PGH}$ is contagious? & & & \multirow{3}{*}{0.009} \\
\hline & No & $141(20.95 \%)$ & $450(66.86 \%)$ & \\
\hline & Yes & $33(4.90 \%)$ & 49 (7.28\%) & \\
\hline \multirow{3}{*}{4} & PGH is a sign of old age and loss of health? & & & \multirow{3}{*}{0.215} \\
\hline & No & $62(9.21 \%)$ & $107(15.89 \%)$ & \\
\hline & Yes & $111(16.49 \%)$ & $393(58.39 \%)$ & \\
\hline \multirow{3}{*}{5} & PGH hinders from participating in social activities? & & & \multirow{3}{*}{0.115} \\
\hline & No & $117(17.38 \%)$ & $369(54.82 \%)$ & \\
\hline & Yes & $56(8.32 \%)$ & $130(19.31 \%)$ & \\
\hline
\end{tabular}

TABLE 7: Gender-wise difference in perception to premature greying of hair in study population $(n=673)$

PGH: Premature greying of hair

As seen in Table 8 , there was a statistical difference in psychological impact on both genders who were affected by premature greying of hair, those with premature greying of hair look older than their actual age ( $\mathrm{p}$-value $=0.036)$, whereas no statistical difference was found regarding if they feel guilty/anxiety $(\mathrm{p}$-value = $0.304)$, mood fluctuations due to premature greying of hair ( $\mathrm{p}$-value $=0.135)$, premature greying of hair affects your concentration at work ( $p$-value $=0.678$ ), premature greying of hair affects your interpersonal relationship $(\mathrm{p}$-value $=0.410)$ and if you have tried any treatment for premature greying of hair $(\mathrm{p}$-value $=$ 0.267). 


\section{Cureus}

\begin{tabular}{|c|c|c|c|c|}
\hline Sr. No. & Variable & Gender & & P-value \\
\hline \multirow{4}{*}{1} & & Male & Female & \multirow{4}{*}{0.304} \\
\hline & & No. $\%$ & No. \% & \\
\hline & No & $42(20 \%)$ & $105(50 \%)$ & \\
\hline & Yes & $13(6.19 \%)$ & $50(23.8 \%)$ & \\
\hline \multirow{3}{*}{2} & Fluctuations in mood due to grey hair? & & & \multirow{3}{*}{0.135} \\
\hline & No & $50(23.8 \%)$ & $127(60.4 \%)$ & \\
\hline & Yes & $5(2.3 \%)$ & $28(13.3 \%)$ & \\
\hline \multirow{3}{*}{3} & Does PGH affect your concentration at work? & & & \multirow{3}{*}{0.678} \\
\hline & No & $47(22.3 \%)$ & $127(60.4 \%)$ & \\
\hline & Yes & $8(3.8 \%)$ & $28(13.3 \%)$ & \\
\hline \multirow{3}{*}{4} & Does PGH affect your interpersonal relationship? & & & \multirow{3}{*}{0.410} \\
\hline & No & $43(20.4 \%)$ & $130(61.9 \%)$ & \\
\hline & Yes & $12(5.7 \%)$ & 25 (11.9\%) & \\
\hline \multirow{3}{*}{5} & Tried any treatment? & & & \multirow{3}{*}{0.267} \\
\hline & No & $44(20.9 \%)$ & $135(64.2 \%)$ & \\
\hline & Yes & $11(5.2 \%)$ & $20(9.5 \%)$ & \\
\hline \multirow{3}{*}{6} & People think you are much older than your actual age? & & & \multirow{3}{*}{0.036} \\
\hline & No & $34(16.1 \%)$ & $119(56.6 \%)$ & \\
\hline & Yes & $21(10 \%)$ & 36 (17.1\%) & \\
\hline
\end{tabular}

TABLE 8: Gender-wise difference in psychological impact on students affected by premature greying of hair in study population $(n=210)$

PGH: Premature greying of hair

To calculate the self-esteem of the students, traditional Rosenberg Self-Esteem Scale (RSES) was used. This scale has been used traditionally to estimate self-esteem. In this scale, 10 questions were used with a maximum score of 30 . Score below 15 indicates low self-esteem. All students were allowed to use this tool. Students were divided into two categories, i.e., students affected and students not affected by premature greying of hair. Those students who were affected by premature greying of hair yielded a mean score of 20.27 whereas students who were not affected by premature greying of hair yielded a mean score of 19.3. No positive correlation was found between low self-esteem and premature greying of hair. Moreover, it yielded a p-value of 0.23 which is statistically insignificant. See Table 9.

Mean score using RSES

Students affected by PGH

20.27

Students not affected by PGH

19.3

\section{TABLE 9: Rosenberg self-esteem scale}

PGH: Premature greying of hair; RSES: Rosenberg self-esteem scale.

\section{Discussion}


A study was conducted on the medical students of Foundation University Medical College. The aim of this study was to assess the general awareness regarding PGH and the common opinions regarding causes of premature greying, as well as its psychological and socio-cultural effects on students.

Canities is a natural phenomenon commonly associated with the process of human aging. Hair plays a major role in our overall appearance especially in women as they tend to base their dignity on their appearance. Premature canities are becoming increasingly prevalent, leading to issues of low self-esteem, poor quality of life and poor health. People suffering from PGH think that they are often noticed because of their imperfect hair, leading to a feeling of low self-esteem [10].

Less than one-third (31.2\%) of our respondents reported to experiencing premature greying of hair. A notable finding of our research was that it was more prevalent in females as compared to males. In our study, it was revealed that $73.8 \%$ of the affected students were females. Whereas according to the case control study conducted in 2016-2017 in North India, it was found that males are more affected by PGH, i.e., 55\% [11]. This high percentage in our setting can be justified by considering the fact that male to female ratio in our study was more inclined towards female gender (74.3\% females and $25.7 \%$ males). When asked at what age they consider greying of hair to be premature, a majority of students considered the ages of 16-20 years as premature, while only a few considered the age of PGH to be above 30 . This shows adequate general knowledge of the students. More than half of the students said that people with PGH were often noticed and commented upon by others. This finding has been supported by a study conducted by The University of Delhi in Northern India which reported that people with PGH had to face embarrassment as well as mockery from both peers and seniors [12]. Almost $12 \%$ of students said that they believed PGH was contagious whereas in Northern India they found that one-third of their sample population considered PGH as contagious. The reason behind this difference could be that the present study has been conducted on medical students and therefore it is more logical for them to believe that greying of hair is not contagious [12]. More than half of the students considered PGH to be indicative of old age and loss of health. Nearly three-fourths of our sample population reported that this condition did not affect their participation in social activities. More than half of the subjects of our research sample disagreed with the statement that PGH is associated with lack of self-care. Out of the remaining subjects, around one-third of the students considered use of hair products as a cause of PGH. With regards to evaluation of the factors that participate in premature greying of hair, the research conducted by Tobin on the aging of hair follicle pigmentation system stated that genetics play a role in premature greying of hair because it is inherited as an autosomal dominant trait [13]. This means that either of your close relatives, siblings or parents might have a history of premature greying of hair. First-degree relatives are at a higher risk of having premature hair greying followed by the secondand third-degree relatives. A study conducted among men under the age of 30 also suggested that an association with family history plays a role in premature greying of hair [14]. Premature greying of hair is an independent trait and does not present with any other abnormality. A majority of the respondents in this study were of the opinion that genetics play a vital role in PGH. Smoking has the tendency to cause obvious changes in the hair pigmentation leading to premature greying. The research conducted in our university showed that the majority of the students did not consider smoking as a factor that can influence premature greying. Chronic smoking was found to have a strong association with premature greying of hair as it causes impairment of the regenerative capacity of stem cells, which was supported by the studies conducted in Korea and Jordan $[14,15]$. The role of obesity in premature greying of hair is not well defined because only a few researches have been conducted to support this theory. The research conducted by the hospitals in Korea stated that obesity is an important factor of the phenomenon while the research conducted in our university showed that a major portion of the students did not consider obesity to be an influencing factor [14]. It was seen that malnutrition can be one of the causes of premature greying of hair. Severe loss of important nutrients like calcium, vitamin D3, iron, zinc and copper showed a significant association. It is also observed that people who suffer from premature greying of hair have a deficiency of these minerals [3,16]. Almost one-third of the students who participated in the research conducted in our university, considered malnutrition as a factor causing greying of hair.

On further analysis of the questions asked, specifically from people suffering from PGH, it was observed that more than half of them started experiencing PGH between the ages of 16-20 years. This is in accordance with another research that labelled 20 in Caucasians as the age for premature greying of hair [17]. Less than half of these individuals feel the need to hide their hair, mostly by styling. This result was supported by the North Indian research which stated that nearly three-fourths of patients tried to conceal their condition by styling and coloring [12]. When asked about the psychological effects of PGH, a majority of the individuals said that it had no effect on their anxiety or mood, and they felt no guilt. This was contradicted by the research conducted by Daulatabad et al. that reported a sense of guilt associated with lack of self-care. This same research stated that the concentration in affected individuals is preserved, which is supported by our own results [12]. The self-esteem of the respondents was evaluated by Rosenberg Self-Esteem Scale. Its effectiveness is validated worldwide as well as nationwide [18-20]. This scale has never been used previously in studies related to premature hair greying. When the self-esteem of the respondents suffering from premature hair greying was compared with those who did not experience PGH, it was observed that there was no significant difference between the two. The study failed to show an association between premature greying of hair and low self-esteem.

The study showed that premature greying affected the socio-cultural spheres of students' lives. Females are 
more prone to developing premature greying of hair. Genetics, malnutrition and erratic lifestyle also play a significant role in premature greying. Statistically significant data was reported in people with premature greying of hair who try to hide it $(\mathrm{p}=0.000)$ and they look older than their age $(\mathrm{p}=0.036)$. No positive correlation was found by using Rosenberg Self-esteem scale.

\section{Conclusions}

The present study concludes that premature greying of hair is mostly seen between 16-20 years of age, with females being more prone to developing premature grey hair. Genetics plays an important role in premature greying of hair. Those with premature greying often get noticed for it, causing a hindrance in their social activities. Statistical difference was observed in 'people with premature greying of hair who try to hide it' and 'they look older than their age'.

\section{Appendices}

We recommend that research on extensive population or on a larger sample size should be conducted. As this research on premature canities is one of its kind in Pakistan, further research on this topic should be greatly encouraged. As premature canities causes a hindrance in social activities, the affected individual should be encouraged to participate in more social events and provided an equal opportunity to compete.

\section{Additional Information \\ Disclosures}

Human subjects: Consent was obtained by all participants in this study. Animal subjects: All authors have confirmed that this study did not involve animal subjects or tissue. Conflicts of interest: In compliance with the ICMJE uniform disclosure form, all authors declare the following: Payment/services info: All authors have declared that no financial support was received from any organization for the submitted work. Financial relationships: All authors have declared that they have no financial relationships at present or within the previous three years with any organizations that might have an interest in the submitted work. Other relationships: All authors have declared that there are no other relationships or activities that could appear to have influenced the submitted work.

\section{References}

1. McEvoy B, Beleza S, Shriver MD: The genetic architecture of normal variation in human pigmentation: an evolutionary perspective and model. Hum Mol Genet. 2006, 15:176-181. 10.1093/hmg/ddl217

2. Commo S, Gaillard O, Bernard BA: Human hair greying is linked to a specific depletion of hair follicle melanocytes affecting both the bulb and the outer root sheath. Br J Dermatol. 2004, 150:435-443. 10.1046/j.1365-2133.2004.05787.x

3. Bhat RM, Sharma R, Pinto AC, Dandekeri S, Martis J: Epidemiological and investigative study of premature graying of hair in higher secondary and pre-university school children. Int J Trichol. 2013, 5:17-21. 10.4103/0974-7753.114706

4. Arck PC, Overall R, Spatz K, et al.: Towards a "free radical theory of graying": melanocyte apoptosis in the aging human hair follicle is an indicator of oxidative stress induced tissue damage. FASEB J. 2006, 20:15671569. 10.1096/fj.05-4039fje

5. Rosen CJ, Holick MF, Millard PS: Premature graying of hair is a risk marker for osteopenia . J Clin Endocrinol Metab. 1994, 79:854-857. 10.1210/jcem.79.3.8077373

6. Schnohr P, Lange P, Nyboe I, Appleyard M, Jensen G: Gray hair, baldness, and wrinkles in relation to myocardial infarction: the Copenhagen City Heart Study. Am Heart J. 1995, 130:1003-1010. 10.1016/00028703(95)90201-5

7. Trüeb RM: Pharmacologic interventions in aging hair . Clin Interv Aging. 2006, 1:121-129.

8. Bilgiç Ö: Do you know this syndrome? Werner syndrome. An Bras Dermatol. 2017, 92:271-272. 10.1590/abd1806-4841.20174640

9. Pandhi D, Khanna D: Premature graying of hair. Indian J Dermatol Venereol Leprol. 2013, 79:641-653. 10.4103/0378-6323.116733

10. Al-Mutairi N, Eldin ON: Clinical profile and impact on quality of life: seven years experience with patients of alopecia areata. Indian J Dermatol Venereol Leprol. 2011, 77:489-493. 10.4103/0378-6323.82411

11. Sharma N, Dogra D: Association of epidemiological and biochemical factors with premature graying of hair: a case-control study. Int J Trichol. 2018, 10:211-217. 10.4103/ijt.ijt 3918

12. Daulatabad D, Grover C, Singal A: Quality of life and psychological impact of premature canities: a study from North India. Pigment Int. 2016, 3:24-28. 10.4103/2349-5847.184267

13. Tobin DJ: Aging of the hair follicle pigmentation system . Int J Trichol. 2009, 1:83-93. 10.4103/09747753.58550

14. Shin H, Ryu HH, Yoon J, et al.: Association of premature hair graying with family history, smoking, and obesity: a cross-sectional study. J Am Acad Dermatol. 2015, 72:321-327. 10.1016/j.jaad.2014.11.008

15. Zayed AA, Shahait AD, Ayoub MN, Yousef AM: Smokers' hair: does smoking cause premature hair graying? . Indian Dermatol Online J. 2013, 4:90-92. 10.4103/2229-5178.110586

16. Naieni FF, Ebrahimi B, Vakilian HR, Shahmoradi Z: Serum iron, zinc, and copper concentration in premature graying of hair. Biol Trace Elem Res. 2012, 146:30-34. 10.1007/s12011-011-9223-6

17. Tobin DJ, Paus R: Graying: gerontobiology of the hair follicle pigmentary unit . Exp Gerontol. 2001, 36:29-54. 10.1016/S0531-5565(00)00210-2

18. Martín-Albo J, Núñez JL, Navarro JG, Grijalvo F: The Rosenberg Self-Esteem Scale: translation and 


\section{Cureus}

validation in university students. Span J Psychol. 2007, 10:458-467. 10.1017/S1138741600006727

19. Eklund M, Bäckström M, Hansson L: Psychometric evaluation of the Swedish version of Rosenberg's selfesteem scale. Nord J Psychiatry. 2018, 72:318-324. 10.1080/08039488.2018.1457177

20. Rizwan M, Malik S, Malik NJ, Siddiqui RS: Urdu rosenberg self-esteem scale: an analysis of reliability and validity in Pakistan. Sociol Int J. 2017, 1:56-61. 10.15406/sij.2017.01.00010 